\title{
Determination of Fluoride Using Ion-selective Electrodes in the Presence of Aluminum
}

\author{
Siqingaowa BorJigin, ${ }^{*}$ Yuuta Ashimura, ${ }^{* *}$ Toshiaki Yoshioka, ${ }^{* \dagger}$ and Tadaaki MizoguchI** \\ *Graduate School of Environmental Studies, Tohoku University, 6-6-7 Aramaki Aza Aoba, Aoba, \\ Sendai 980-8579, Japan \\ **Environment Conservation Research Institute, Tohoku University, 6-6-11 Aramaki Aza Aoba, Aoba, \\ Sendai 980-8579, Japan
}

\begin{abstract}
We describe a method for determining fluoride with ion-selective electrodes (ISEs). Tartrate and Tris-based total ionic strength adjustment buffers (TISABs) were found to lower the interference from aluminum to a greater extent than conventional citrate-based TISABs. We adopted a solid TISAB addition method that is simple to perform, and can be carried out without lowering the level of fluoride. The apparent recovery of fluoride was $95 \%$ or higher, even at $500 \mathrm{mg} \mathrm{L}^{-1}$ of $\mathrm{Al}^{3+}$ when a tartrate and Tris-based TISAB was used. Interferences from common ions were not observed at $100 \mathrm{mg} \mathrm{L}^{-1}$ levels. We determined the fluoride content in solid silicate samples with ISEs without preliminary steam distillation after alkali fusion processing. Adding a solid TISAB mixture consisting of tartaric acid, sodium tartrate, and Tris, however, eliminated any interference from high levels of aluminum and sodium and potassium carbonates. The proposed analytical method was also applied to the determination of fluoride in geochemical reference samples.
\end{abstract}

(Received January 30, 2009; Accepted November 4, 2009; Published December 10, 2009)

\section{Introduction}

The amount of fluoride in coal, its ashes and flue gases ${ }^{1,2}$ ranges from dozens to several hundred $\mathrm{mg} \mathrm{kg}^{-1}$. Most of the fluorine is removed upstream at desulfurization plants by pre-scrubbers during the removal of dust, and by a reduction of the flue-gas temperature. The pre-scrubber circulation liquid is highly acidic, i.e., $\mathrm{pH} 1$, and the wastewater from a pre-scrubber typically contains $100-1500 \mathrm{mg} \mathrm{L}^{-1}$ fluoride and 200 $1500 \mathrm{mg} \mathrm{L}^{-1}$ aluminum. Therefore, it is necessary to also analyze low fluoride concentrations in liquids precisely, even in the presence of high concentrations of aluminum and other coexisting ions.

Ion-selective electrodes (ISE) have been widely used for determining fluoride since Frant and Ross ${ }^{3}$ first constructed a fluoride-ISE. Aluminum, however, interferes with the determination of fluoride by ISEs due to the formation of stable fluoroaluminate complexes. As described elsewhere, ${ }^{4,5}$ fluoride must be separated from aluminum by steam distillation prior to its determination by ISEs.

This difficulty can be overcome to some extent by adding a suitable masking agent to a total ionic strength adjustment buffer (TISAB). Various complexing reagents have been used, ${ }^{6-14}$ the most common being citrate ${ }^{11,12}$ and 1,2-diaminocyclohexane$N, N, N^{\prime}, N^{\prime}$-tetraacetic acid (CyDTA). ${ }^{13,14}$ We have investigated the efficiency of four kinds of TISABs which have been reported previously to possess high capabilities of reducing the interference from aluminum. We also found that tartrate and Tris-based TISAB-IV (disodium tartrate, tris(hydroxymethyl)

$\dagger$ To whom correspondence should be addressed.

E-mail: yoshioka@env.che.tohoku.ac.jp methylamine (Tris), hydrochloric acid) reduced the interference from aluminum to a greater extent than the other three TISABs. Corbillon et al. ${ }^{15}$ reported that TISAB-IV could be used at a $\mathrm{pH}$ of 8.4 to complex aluminum ions. Although TISAB-IV has been adopted by the ASTM, ${ }^{4}$ the practical applications of TISAB-IV are currently limited ${ }^{16}$ due to a lack of published data.

The objective of the present study was to obtain basic data regarding the determination of fluoride by ISEs in the presence of aluminum with tartrate and Tris-based TISAB. The decomplexing abilities of tartrate and Tris-based TISABs were compared with those of other TISABs.

We adopted an analytical method in which solid chemical reagents are added directly to the sample solution to adjust the $\mathrm{pH}$ and total ionic strength without using strong acids and bases, such as hydrochloric acid and sodium hydroxide, respectively. Adding a solid TISAB mixture consisting of tartaric acid, sodium tartrate, and Tris, however, eliminated any interference from high levels of aluminum and sodium and potassium carbonates due to the flux used during alkali fusion processing of solid silicate samples. The proposed analytical method was also applied to the determination of fluoride in geochemical reference samples.

\section{Experimental}

\section{Apparatus}

The fluoride concentration was measured using a fluoride-ISE and portable ion-pH meter (F-2021 and IM-22P; DKK-TOA Co.). 
Table 1 Composition of reference samples

\begin{tabular}{|c|c|c|c|c|c|c|c|c|c|c|c|c|c|}
\hline \multirow{2}{*}{ Sample } & \multicolumn{4}{|c|}{ Recommended value } & \multicolumn{9}{|c|}{ Original data used for determining recommended $\mathrm{F}$ content $/ \mathrm{mg} \mathrm{kg}^{-1}$} \\
\hline & $\mathrm{Al}_{2} \mathrm{O}_{3}, \mathrm{wt} \%$ & $\mathrm{CaO}, \mathrm{wt} \%$ & $\mathrm{SiO}_{2}, \mathrm{wt} \%$ & $\mathrm{~F} / \mathrm{mg} \mathrm{kg}^{-1}$ & No. 1 & 2 & 3 & 4 & 5 & 6 & 7 & 8 & 9 \\
\hline JB-3 & 17.2 & 9.79 & 51.0 & 253 & 243 & 300 & 330 & 200 & 308 & 246 & 210 & 190 & 251 \\
\hline JLk-1 & 16.7 & 0.69 & 57.2 & 589 & 510 & 650 & 490 & 657 & 640 & & & & \\
\hline JSd-3 & 9.91 & 1.17 & 76.0 & 3200 & 2430 & 3960 & 1200 & 4244 & 4187 & 3348 & & & \\
\hline
\end{tabular}

JB-3: basalt sample, JLk-1: lake sediment sample, JSd-3: stream sediment sample.

\section{Reagents}

Unless otherwise stated, all chemicals were of analytical reagent grade, and were used without further purification. Fluoride-containing geochemical reference samples JB-3 (basalt), JLk-1 (lake sediment), and JSd-3 (stream sediment) were supplied by the National Institute of Advanced Industrial Science and Technology, Geological Survey of Japan. The analytical data of these reference samples are given in Table $1 .{ }^{17}$ Distilled and demineralized water was used throughout this study. A standard fluoride ion solution and TISABs were prepared as follows:

About $2.5 \mathrm{~g}$ of sodium fluoride was heated for $1 \mathrm{~h}$ at $500^{\circ} \mathrm{C}$. Sodium fluoride was accurately weighed $(2.21 \mathrm{~g})$, dissolved in water, and then diluted to $1 \mathrm{~L}$ with water $\left(1000 \mathrm{mg} \mathrm{L}^{-1} \mathrm{~F}^{-}\right.$stock solution).

TISAB-A was the same as that adopted in the Japanese Industrial Standard (JIS) K0102. ${ }^{5}$ Sodium chloride (58 g) and diammonium hydrogencitrate $(1 \mathrm{~g})$ were dissolved in about $800 \mathrm{~mL}$ of water, and $50 \mathrm{~mL}$ of glacial acetic acid was added. The $\mathrm{pH}$ was adjusted to 5.2 with a $20 \%$ sodium hydroxide solution, and the solution was diluted to $1 \mathrm{~L}$ with water.

TISAB-B (TISAB-11, obtained from DKK-TOA Co., Tokyo, Japan) was prepared as follows. ${ }^{18}$ Citric acid (26 g) and sodium citrate dihydrate $(300 \mathrm{~g})$ were dissolved in about $700 \mathrm{~mL}$ of water, the $\mathrm{pH}$ was adjusted to 5.5 with sodium hydroxide solution, and the solution was diluted to $1 \mathrm{~L}$ with water.

TISAB-C was used by Nakajima et al. ${ }^{14}$ to evaluate the decomplexing ability for aluminum. Sodium citrate dihydrate $(147 \mathrm{~g})$, potassium nitrate $(10 \mathrm{~g})$, glacial acetic acid $(28.5 \mathrm{~mL})$, and sodium chloride ( $29 \mathrm{~g}$ ) were dissolved in about $700 \mathrm{~mL}$ of water and diluted to $1 \mathrm{~L}$ with water after adjusting the $\mathrm{pH}$ of the solution to 5.2 with $5 \mathrm{M} \mathrm{NaOH}$.

TISAB-D was used by Corbillon et al., ${ }^{15}$ and prepared as follows. Disodium tartrate dihydrate (230 g), Tris (242 g), and $84 \mathrm{~mL}$ of hydrochloric acid $(37 \%)$ were diluted to $1 \mathrm{~L}$ with water. The $\mathrm{pH}$ of this solution was about 8.4 .

\section{Procedures}

Liquid TISAB addition method. Preparation of calibration curves: Calibration curves were obtained according to the following procedure. Forty-milliliter aliquots of 10 and $100 \mathrm{mg} \mathrm{L}^{-1} \mathrm{~F}^{-}$standard solutions were put into polyethylene beakers, and $10 \mathrm{~mL}$ of TISAB-D was added to each $\mathrm{F}^{-}$standard solution. The corresponding electrode potentials were recorded with an ion meter, and measured approximately 15 min after inserting the electrode into the continuously stirred solution at $23 \pm 1{ }^{\circ} \mathrm{C}$.

The calibration of the ion meter was performed initially with a $10 \mathrm{mg} \mathrm{L}^{-1} \mathrm{~F}^{-}$standard solution, then with a $100 \mathrm{mg} \mathrm{L}^{-1} \mathrm{~F}^{-}$ standard solution, and again with a $10 \mathrm{mg} \mathrm{L}^{-1} \mathrm{~F}^{-}$standard solution to ensure the completeness of the calibration. In some experiments, 1 and $10 \mathrm{mg} \mathrm{L}^{-1} \mathrm{~F}^{-}$standard solutions were used to prepare calibration curves.
Determining the apparent recovery of $\mathrm{F}^{-}$: The effect of coexisting aluminum on the detection degree of $\mathrm{F}^{-}$was determined by adding a desired amount of aluminum to the fluoride containing solution.

Forty-milliliter aliquots of solutions with and without aluminum were put into polyethylene beakers, and $10 \mathrm{~mL}$ of TISAB-D was added. The electrode potential, which was automatically converted to the concentration of fluoride, was recorded $15 \mathrm{~min}$ after inserting the electrode into the solution. The measurements with and without aluminum were compared. Solid TISAB addition method. The analytical procedure was the same as that in the liquid TISAB addition method. The difference was that chemical reagents for adjusting the total ionic strength and $\mathrm{pH}$ were added in the solid state. In a standard procedure, a solid mixture consisting of $0.75 \mathrm{~g}$ tartaric acid, $1.15 \mathrm{~g}$ disodium tartrate dihydrate, $2.42 \mathrm{~g}$ Tris, and $0.58 \mathrm{~g}$ sodium chloride was added to $50 \mathrm{~mL}$ of sample solution gradually, with continuous stirring. The ISE was inserted into the solution after the reagents were dissolved and the indication of the fluoride ion activity was recorded.

\section{Determination of total fluoride in solid silicate samples}

Alkali ion effects. An equimolar mixture of sodium carbonate and potassium carbonate $(2.5 \mathrm{~g}$ total) was dissolved in water, and 1,5 , or $10 \mathrm{~mL}$ of $100 \mathrm{mg} \mathrm{L}^{-1} \mathrm{~F}^{-}$solution was added. The contents were transferred to a $100-\mathrm{mL}$ volumetric flask and diluted to the mark with water. A $50-\mathrm{mL}$ aliquot of this solution was then transferred to a polyethylene beaker. The carbonate was decomposed by slowly adding $3.0 \mathrm{~g}(20 \mathrm{mmol})$ of tartaric acid while gently stirring with a magnetic stirrer.

After the generation of carbon dioxide was complete, $4.6 \mathrm{~g}$ (20 mmol) of sodium tartrate and $4.84 \mathrm{~g}(40 \mathrm{mmol})$ of Tris were added while stirring. The addition of sodium chloride to adjust the ionic strength was omitted, since a large amount of sodium and potassium ions were added in subsequent procedures.

The fluoride ISE was inserted into each solution, and the potential was measured and recorded to generate a calibration curve. The readings were recorded approximately $15 \mathrm{~min}$ after inserting the electrode into the continuously stirred solution.

Coexisting ions effects. An equimolar mixture of sodium carbonate and potassium carbonate $(2.5 \mathrm{~g}$ total) was dissolved in approximately $50 \mathrm{~mL}$ of water and transferred to a $100-\mathrm{mL}$ volumetric flask. The following were also added: $1 \mathrm{~mL}$ of $100 \mathrm{mg} \mathrm{L}^{-1} \mathrm{~F}^{-} \mathrm{NaF}$ solution, $10 \mathrm{~mL}$ of $5000 \mathrm{mg} \mathrm{L}^{-1} \mathrm{Al}^{3+} \mathrm{AlCl}_{3}$ solution, $8 \mathrm{~mL}$ of $5000 \mathrm{mg} \mathrm{L}^{-1} \mathrm{Ca}^{2+} \mathrm{CaCl}_{2}$ solution, or $10 \mathrm{~mL}$ of $15000 \mathrm{mg} \mathrm{L}^{-1} \mathrm{SiO}_{3}{ }^{2-} \mathrm{Na}_{2} \mathrm{SiO}_{3}$ solution. Each flask was then diluted to the mark with water.

A 50-mL aliquot of this solution was placed into a polyethylene container. Then, $3.0 \mathrm{~g}(20 \mathrm{mmol})$ of tartaric acid, $4.6 \mathrm{~g}$ (20 mmol) of sodium tartrate, and $4.84 \mathrm{~g}(40 \mathrm{mmol})$ of Tris were added to decompose the carbonates and regulate the $\mathrm{pH}$. The concentration of fluoride was determined by inserting the fluoride ISE into the solution. A calibration curve was generated 


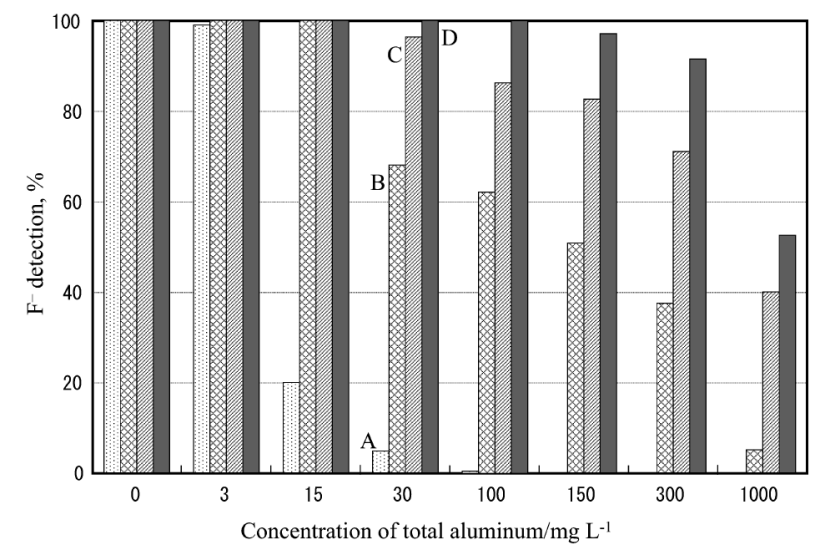

Fig. 1 Relationships between the detection of $\mathrm{F}^{-}$and concentration of aluminum for various kinds of TISABs. Concentration of fluoride in sample solution: $20 \mathrm{mg} / \mathrm{L}$. Kinds of TISABs: A, TISAB-A; B, TISAB-B; C, TISAB-C; D, TISAB-D.

using a solution containing the same amount of sodium carbonate and potassium carbonate.

Analysis of reference materials. In accordance with the procedure by Ogura, ${ }^{14} 2 \mathrm{~g}$ of each sample was ashed in a porcelain crucible by heating for $2 \mathrm{~h}$ at $550^{\circ} \mathrm{C}$ in an electric furnace. The weight loss recorded during heating was used to calibrate the final analytical results.

A portion of each ashed sample $(0.5 \mathrm{~g})$, preferably containing more than $0.2 \mathrm{mg}$ of fluoride, was weighed in a platinum crucible. An equimolar mixture of sodium carbonate and potassium carbonate ( $4 \mathrm{~g}$ total) was added to the sample and mixed well with a glass rod. One gram of the carbonate mixture was placed over the sample. The sample was melted over a Bunsen burner and heated for an additional $30 \mathrm{~min}$. After cooling, the sample was dissolved in $100 \mathrm{~mL}$ of hot water, transferred to a $200-\mathrm{mL}$ volumetric flask, diluted to the mark with water, and filtered through a fine filter paper. A $50-\mathrm{mL}$ aliquot of the filtrate was transferred to a polyethylene container. As described above, $3.0 \mathrm{~g}$ of tartaric acid, $4.6 \mathrm{~g}$ of sodium tartrate, and $4.84 \mathrm{~g}$ of Tris were added to the test solution prior to analysis. The fluoride concentration was determined using the fluoride ISE, and a calibration curve was generated using a solution containing the same amount of sodium carbonate and potassium carbonate. The addition of sodium chloride to adjust the ionic strength was omitted.

\section{Results and Discussion}

Effect of various kinds of TISABs on the apparent recovery of $F^{-}$ in the presence of aluminum

A suitable volume of a mixed solution of sodium fluoride and aluminum chloride containing $20 \mathrm{mg} \mathrm{L}^{-1}$ of $\mathrm{F}^{-}$and the desired amount of $\mathrm{Al}^{3+}\left(0,3,15,30,150,300\right.$, or $\left.1000 \mathrm{mg} \mathrm{L}^{-1}\right)$ was put into a polyethylene beaker, and a fixed volume of TISAB was added according to the original procedure. The TISAB/sample solution ratios were 5/50, 50/50, 40/20 and 10/40 $\left(\mathrm{mL} \mathrm{mL}^{-1}\right)$ for TISAB-A, B, C and D, respectively. The ratios of the fluoride concentration detected in the presence of aluminum to that in the absence of aluminum were determined.

The relationships between the apparent recovery of $\mathrm{F}^{-}$and aluminum concentration for various kinds of TISABs are shown in Fig. 1. In the case of TISAB-A, about $20 \%$ of the fluoride

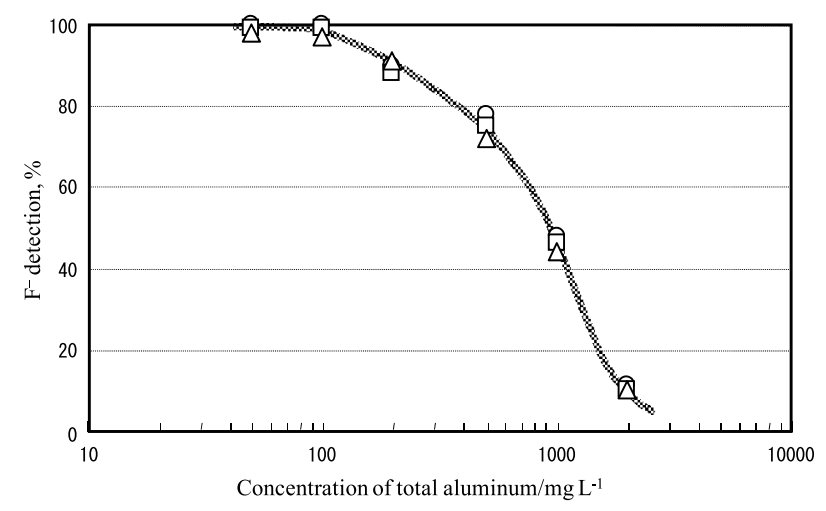

Fig. 2 Effect of the concentration of aluminum on the detection of $\mathrm{F}^{-}$at various levels of fluoride concentration. TISAB added: $10 \mathrm{~mL}$ of TISAB-D to $40 \mathrm{~mL}$ of sample solution. Concentration of fluoride in sample solution $\left(\mathrm{mg} \mathrm{L}^{-1}\right)$ : $\bigcirc 1, \square 10, \triangle 100$.

present was detected at an $\mathrm{Al}^{3+}$ concentration of $15 \mathrm{mg} \mathrm{L}^{-1}$. In the case of TISAB-B, which had a higher citrate content, the effect of aluminum was lowered, making it possible to detect $100 \%$ of the fluoride. The apparent recovery of $\mathrm{F}^{-}$was about 68 and $62 \%$ at $\mathrm{Al}^{3+}$ concentrations of 30 and $100 \mathrm{mg} \mathrm{L}^{-1}$, respectively. In the case of TISAB-C, ${ }^{14}$ which was characterized by a large amount of added citrate, the effect of aluminum was much lower than with TISAB-B. The apparent recovery of $\mathrm{F}^{-}$ was about $96 \%$ at an $\mathrm{Al}^{3+}$ concentration of $30 \mathrm{mg} \mathrm{L}^{-1}$. The apparent recovery of $\mathrm{F}^{-}$decreased to $86,83,71$, and $40 \%$ at $\mathrm{Al}^{3+}$ concentrations of $100,150,300$, and $1000 \mathrm{mg} \mathrm{L}^{-1}$, respectively. Note that $40 \mathrm{~mL}$ of TISAB-C was added to $20 \mathrm{~mL}$ of sample solution, resulting in a dilution of one-third.

In the case of TISAB-D, the effect of aluminum was lowered to a great extent. The detection degree of $\mathrm{F}^{-}$was $100 \%$ at an $\mathrm{Al}^{3+}$ concentration of $100 \mathrm{mg} \mathrm{L}^{-1}$ and it decreased just slightly $92 \%$ at an $\mathrm{Al}^{3+}$ concentration of $300 \mathrm{mg} \mathrm{L}^{-1}$.

It has been reported that TISABs containing CyDTA are effective in lowering the effect of aluminum ions. ${ }^{13,19}$ However, according to results from Nakajima et al.,${ }^{14}$ a TISAB containing CyDTA was not as effective as TISAB-C in lowering the effect of aluminum ions. Van den Hoop et al. ${ }^{20}$ also reported that TISAB containing CyDTA was not able to decomplex all of the fluoride bound by aluminum.

We concluded that the most effective TISAB, lowering the effect of aluminum ions on the detection of $\mathrm{F}^{-}$, was TISAB-D, a mixed solution of disodium tartrate, Tris, and hydrochloric acid. Various aspects in the determination of $\mathrm{F}^{-}$by ISEs in the presence of aluminum ions are discussed in the following sections.

Effect of various factors on the determination of $F^{-}$in the presence of aluminum using liquid TISAB addition method

Concentration of aluminum. A 40-mL volume of solution containing 1,10 , or $100 \mathrm{mg} \mathrm{L}^{-1}$ of $\mathrm{F}^{-}$and $50,100,200,500$, 1000 , or $2000 \mathrm{mg} \mathrm{L}^{-1}$ of $\mathrm{Al}^{3+}$ was put into a polyethylene beaker, and $10 \mathrm{~mL}$ of TISAB-D was added. The recovery rate of fluoride was determined according to the experimental procedure for liquid TISAB addition method. The experimental results are shown in Fig. 2.

The detection of $\mathrm{F}^{-}$was scarcely affected by the $\mathrm{F}^{-}$ concentration, but was drastically influenced by the aluminum concentration. The apparent recovery of $\mathrm{F}^{-}$was almost $100 \%$ at $100 \mathrm{mg} \mathrm{L}^{-1}$ of $\mathrm{Al}^{3+}$, and $72-80 \%$ and $42-48 \%$ at 500 and 


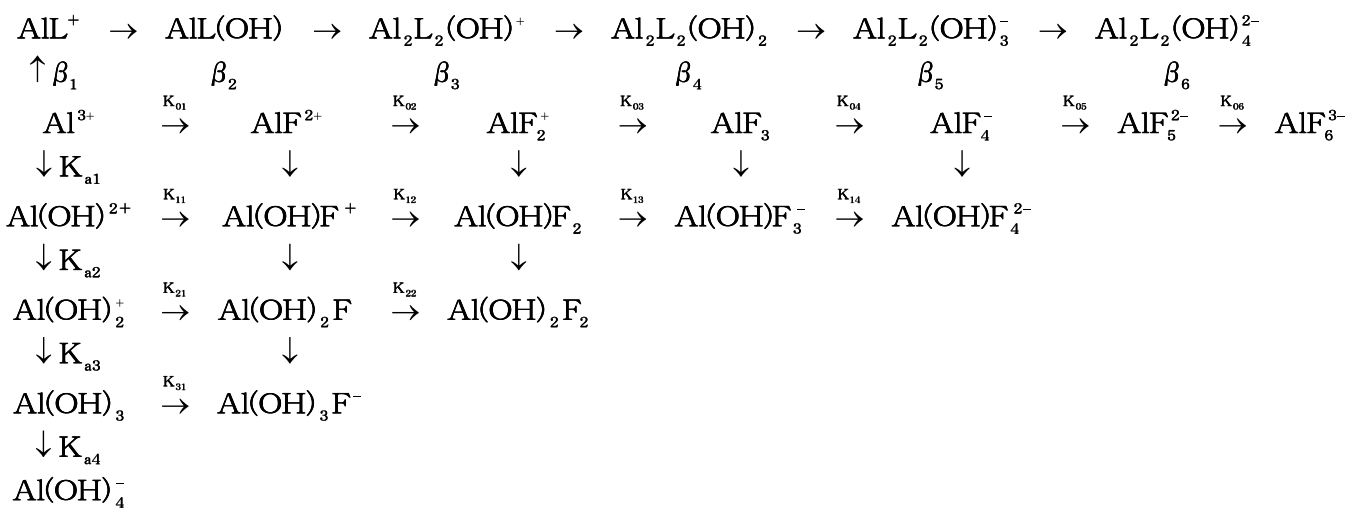

Fig. 3 Scheme for the formation of mixed complexes of $\mathrm{OH}^{-}, \mathrm{F}^{-}$, and tartrate $(\mathrm{L})$ with aluminum. $K_{\mathrm{a} 1}-K_{\mathrm{a} 4}, K_{01}-K_{06}, K_{11}-K_{14}, K_{21}, K_{22}, K_{31}$, stepwise stability constants; ${ }^{21} \beta_{1}-\beta_{6}$, overall stability constants. $^{22}$

$1000 \mathrm{mg} \mathrm{L}^{-1}$ of $\mathrm{Al}^{3+}$, respectively, regardless of the fluoride concentration.

Because the detection of $\mathrm{F}^{-}$was mainly limited by the aluminum concentration, and independent of the $\mathrm{F}^{-}$ concentration, the effect of aluminum ions can be lowered by diluting the solution, providing that the $\mathrm{F}^{-}$concentration remains within a detectable range.

In the case of citrate-based TISAB, the effect of aluminum depended on the level of the fluoride concentration, and aluminum tolerances decreased sharply at $\mathrm{pH} 5.5$ compared to those at $\mathrm{pH} 8 .{ }^{12}$ In the present case shown in Fig. 2, the effect of aluminum at $\mathrm{pH} 8.4$ was practically independent of fluoride concentrations ranging from 1 to $100 \mathrm{mg} \mathrm{L}^{-1}$.

Aluminum speciation studies have been carried out in aluminum(III)-fluoride-hydroxide and aluminum(III)-tartrate (L)-hydroxide systems by Martin, ${ }^{21}$ and Desroches et al. ${ }^{22}$ respectively. The complexes and their stability constants are shown in Fig. 3. The material balances for the total fluoride $\left[\mathrm{F}^{-}\right]_{\mathrm{t}}$ and aluminum $\left[\mathrm{Al}^{3+}\right]_{\mathrm{t}}$ are shown by the following relationships:

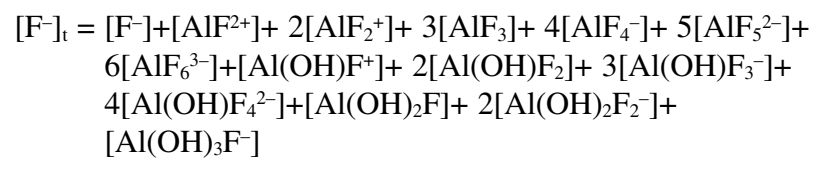

$\left[\mathrm{Al}^{3+}\right]_{\mathrm{t}}=\left[\mathrm{Al}^{3+}\right]+\left[\mathrm{AlOH}^{2+}\right]+\left[\mathrm{Al}(\mathrm{OH})_{2}^{+}\right]+\left[\mathrm{Al}(\mathrm{OH})_{3}\right]+\left[\mathrm{Al}(\mathrm{OH})_{4}^{-}\right]+$ $\left[\mathrm{AlF}^{2+}\right]+\left[\mathrm{AlF}_{2}{ }^{+}\right]+\left[\mathrm{AlF}_{3}\right]+\left[\mathrm{AlF}_{4}{ }^{-}\right]+\left[\mathrm{AlF}_{5}{ }^{2-}\right]+\left[\mathrm{AlF}_{6}{ }^{3-}\right]+$ $\left[\mathrm{Al}(\mathrm{OH}) \mathrm{F}^{+}\right]+\left[\mathrm{Al}(\mathrm{OH}) \mathrm{F}_{2}\right]+\left[\mathrm{Al}(\mathrm{OH}) \mathrm{F}_{3}^{-}\right]+\left[\mathrm{Al}(\mathrm{OH}) \mathrm{F}_{4}{ }^{2-}\right]+$ $\left[\mathrm{Al}(\mathrm{OH})_{2} \mathrm{~F}\right]+\left[\mathrm{Al}(\mathrm{OH})_{2} \mathrm{~F}_{2}^{-}\right]+\left[\mathrm{Al}(\mathrm{OH})_{3} \mathrm{~F}^{-}\right]+\left[\mathrm{AlL}^{+}\right]+$ $[\mathrm{AlL}(\mathrm{OH})]+2\left[\mathrm{Al}_{2} \mathrm{~L}_{2}(\mathrm{OH})^{+}\right]+2\left[\mathrm{Al}_{2} \mathrm{~L}_{2}(\mathrm{OH})_{2}\right]+$ $2\left[\mathrm{Al}_{2} \mathrm{~L}_{2}(\mathrm{OH})_{3}^{-}\right]+2\left[\mathrm{Al}_{2} \mathrm{~L}_{2}(\mathrm{OH})_{4}{ }^{2-}\right]$

The fractions of free fluoride were calculated against the total concentration of aluminum up to $1000 \mathrm{mg} \mathrm{L}^{-1} \mathrm{Al}^{3+}$ at a constant $\mathrm{pH}$ of 8.4, a total fluoride concentration of $1-100 \mathrm{mg} \mathrm{L}^{-1}$, and a tartrate concentration of $0.2 \mathrm{~mol} \mathrm{~L}^{-1}$ (see Ref. 23 for the detailed calculation procedure). It is evident from the results shown in Fig. 4 that the fraction of free fluoride decreases to values between 40.3 and $46.9 \%$ in the absence of tartrate and a total aluminum concentration of $100 \mathrm{mg} \mathrm{L}^{-1}$. The effect of the total fluoride concentration on the fraction of free fluoride was relatively low at fixed aluminum concentrations.

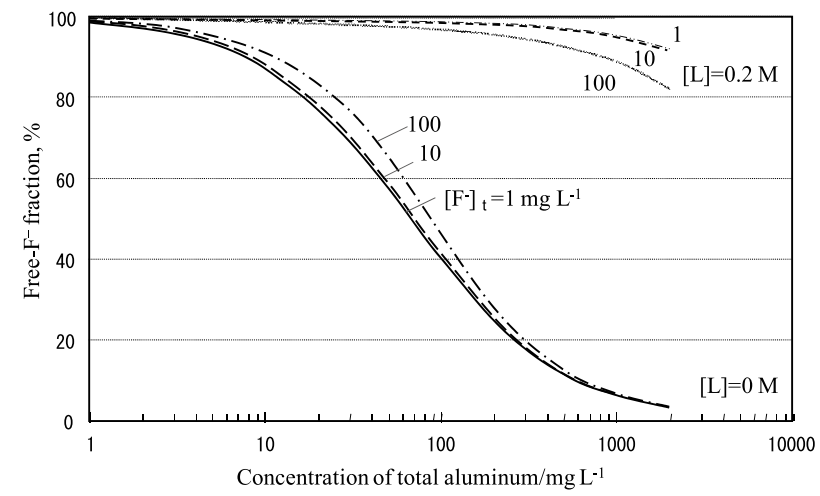

Fig. 4 Fraction of free fluoride in dependence of the aluminium concentration in the presence and absence of tartrate $(\mathrm{L})$ at $\mathrm{pH}$ 8.4.

On the other hand, the fraction of free fluoride reached $97 \%$ at a total fluoride concentration of $10 \mathrm{mg} \mathrm{L}^{-1}$ and a total aluminum concentration of $1000 \mathrm{mg} \mathrm{L}^{-1}$ when $0.2 \mathrm{~mol} \mathrm{~L}^{-1}$ of tartrate was present. These results show that tartrate has a strong ability to decompose fluoroaluminates. The equilibrium calculation showed that a strong aluminum tartrate complex was formed $\left(\mathrm{Al}_{2} \mathrm{~L}_{2}(\mathrm{OH})_{4}{ }^{2-}\right)$ instead.

The results from the calculation also showed that the main fluoride containing species was $\mathrm{Al}(\mathrm{OH})_{3} \mathrm{~F}^{-}$, and that the effect of the total fluoride concentration level on the fraction of free fluoride was relatively low, regardless of the presence of tartrate. This tendency was also observed in the experimental results (see Fig. 2). However, the detection degree of free fluoride obtained by the experiments was smaller than the calculated values at $0.2 \mathrm{~mol} \mathrm{~L}^{-1}$ of tatrate. This may be related to the facts that the activity coefficients were not taken into consideration in the present study, and that some other fluoride-containing complexes that were not shown in Fig. 3 may possibly be present in solution.

Amount of TISAB-D added. A 40-mL volume of a solution containing $20 \mathrm{mg} \mathrm{L}^{-1}$ of $\mathrm{F}^{-}$and 20,100 , or $1000 \mathrm{mg} \mathrm{L}^{-1}$ of $\mathrm{Al}^{3+}$ was put into a polyethylene beaker, and various amounts of TISAB-D were added to it. The recovery rate of fluoride was determined according to the experimental procedure described in the experimental procedure for the liquid method. 


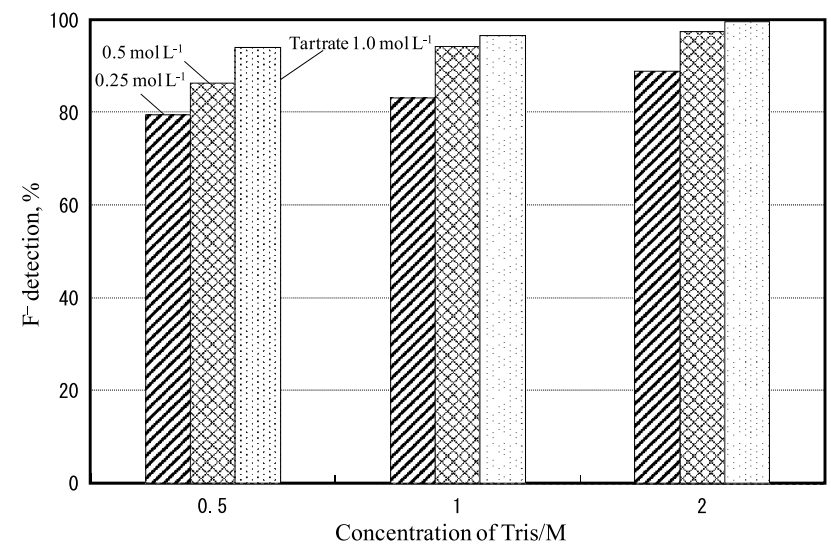

Fig. 5 Effect of the TISAB composition on the detection of $\mathrm{F}^{-}$in the presence of aluminum. Concentration of fluoride in the sample solution, $20 \mathrm{mg} \mathrm{L}^{-1}$; concentration of aluminum in sample solution, $100 \mathrm{mg} \mathrm{L}^{-1}$; amount of TISAB added, $10-40 \mathrm{~mL}$ of sample solution.

The apparent recovery of $\mathrm{F}^{-}$was about $100 \%$, even when $2.5 \mathrm{~mL}$ of TISAB-D was added to $40 \mathrm{~mL}$ of a sample solution containing $20 \mathrm{mg} \mathrm{L}^{-1} \mathrm{Al}^{3+}$. The recovery rate of fluoride decreased to 81 and $95 \%$ when 2.5 and $5 \mathrm{~mL}$ of TISAB-D, respectively, were added to $40 \mathrm{~mL}$ of a sample solution containing $100 \mathrm{mg} \mathrm{L}^{-1} \mathrm{Al}^{3+}$. The recovery rate reached more than $99 \%$ at an $\mathrm{Al}^{3+}$ concentration of $100 \mathrm{mg} \mathrm{L}^{-1}$ when $7.5 \mathrm{~mL}$ or more of TISAB-D was added. However, the recovery rate decreased to $92 \%$ when $30 \mathrm{~mL}$ of TISAB-D was added to $40 \mathrm{~mL}$ of a sample containing $1000 \mathrm{mg} \mathrm{L}^{-1} \mathrm{Al}^{3+}$.

According to the calculation results, the ratio of free fluoride reached $98.2 \%$ in the last case. This discrepancy might have been caused by the fact that also other chemical species might be present in the solution, and by assuming the activity coefficients of all chemical species to be one.

TISAB composition. The concentrations of sodium tartrate and Tris in the standard TISAB-IV solution are 1 and $2 \mathrm{M}$, respectively. Nine kinds of TISABs were prepared by decreasing sodium tartrate and/or Tris. The $\mathrm{pH}$ value of each TISAB was adjusted to 8.4 with hydrochloric acid. A $40-\mathrm{mL}$ volume of a solution containing $20 \mathrm{mg} \mathrm{L}^{-1}$ of $\mathrm{F}^{-}$and $100 \mathrm{mg} \mathrm{L}^{-1} \mathrm{of} \mathrm{Al}^{3+}$ was put into a polyethylene beaker, and $10 \mathrm{~mL}$ of each TISAB was added. The recovery rate of fluoride was determined according to the method described in the experimental section for the addition of liquid TISAB. The experimental results are shown in Fig. 5.

The concentration of Tris in standard TISAB-D was $2 \mathrm{M}$. The difference in $\mathrm{F}^{-}$detection was as small as $6 \%$ between $2 \mathrm{M}$ and $0.5 \mathrm{M}$ Tris at an $\mathrm{Al}^{3+}$ concentration of $100 \mathrm{mg} \mathrm{L}^{-1}$ when the concentration of sodium tartrate was fixed at $1 \mathrm{M}$. However, the effect of aluminum was very clear when the concentration of sodium tartrate was reduced from $1.0 \mathrm{M}$ to 0.5 or $0.25 \mathrm{M}$, showing that tartrate ions were effective at decomplexing aluminum.

The recovery rate of fluoride decreased to $39 \%$ in the presence of $100 \mathrm{mg} \mathrm{L}^{-1}$ aluminum when Tris and hydrochloric acid were used for adjusting the $\mathrm{pH}$ to 8.4 without tartrate. It is obvious that tartrate plays an important role in decomposing fluoroaluminate complexes at $\mathrm{pH}$ 8.4. However, citrate was as effective as tartrate if used in an equimolar amount. While no compelling reason exists to replace tartrate with citrate, or any other organic acid in TISAB-IV, a further investigation of citrate-based TISAB was omitted.
Determination of $F^{-}$using the solid TISAB addition method

Three kinds of methods were considered for decreasing the effect of aluminum in the determination of fluoride using an ISE method. In the first method, the sample was simply diluted with water to a suitable concentration, while in the second one the amount of TISAB was increased. If possible, measuring the concentration of $\mathrm{F}^{-}$ions at several milligrams per liter or higher is desirable because lower $\mathrm{F}^{-}$concentrations result in a slight fluctuation of the measured values due to a slow ISE response. The increase in the amount of TISAB corresponded to a decrease in the concentration of $\mathrm{F}^{-}$to be analyzed. The third method was to elevate the concentration of the effective constituents in TISAB.

In this respect, adding TISAB constituents in a solid state instead of in their mixed solution has several advantages, including attainment of high $\mathrm{F}^{-}$concentration, simplification of the procedure for adjusting the total ion strength, and omitting the usage of hazardous chemicals, such as hydrochloric acid and sodium hydroxide.

Sample solutions containing less than $1 \mathrm{mg} \mathrm{L}^{-1} \mathrm{~F}^{-}$, with $\mathrm{Al}^{3+}$ concentrations of more than an order of magnitude higher, are common in the analysis of solid silicate materials, such as fly ash and soil. In these cases, a method entailing minimal sample dilution carries a definite advantage. The application of this technique to silicate samples will be presented in later.

Ten milliliters of TISAB-D contain $10 \mathrm{mmol}$ of disodium tartrate dihydrate, $20 \mathrm{mmol}$ of Tris, and $10 \mathrm{mmol}$ of hydrochloric acid. The same composition is obtained by mixing the following reagents: $5 \mathrm{mmol}(0.75 \mathrm{~g})$ of tartaric acid, $5 \mathrm{mmol}(1.15 \mathrm{~g})$ of disodium tartrate dihydrate, $20 \mathrm{mmol}(2.42 \mathrm{~g})$ of Tris, and $10 \mathrm{mmol}(0.58 \mathrm{~g})$ of sodium chloride.

The effect of the aluminum concentration on the detection of $\mathrm{F}^{-}$was investigated at a standard amount of tartrate and fourtimes the standard amount of tartrate. The first and second acid dissociation constants $\left(\mathrm{p} K_{\mathrm{a}}\right)$ of tartaric acid are 2.87 and 3.97, ${ }^{24}$ respectively. As such, it dissociates almost completely under the conditions for the determination of $\mathrm{F}^{-}$using ISEs, showing practically no change in the $\mathrm{pH}$ value when dissolved in an alkaline solution. Therefore, disodium tartrate dihydrate could be used as an additional tartrate source without changing the $\mathrm{pH}$ when the amount of total tartrate added was four-times the standard amount.

A $50-\mathrm{mL}$ volume of a solution containing $10 \mathrm{mg} \mathrm{L}^{-1}$ of F$^{-}$and $50-1000 \mathrm{mg} \mathrm{L}^{-1}$ of $\mathrm{Al}^{3+}$ was put into a polyethylene beaker, and a mixed powder consisting of $0.75 \mathrm{~g}$ tartaric acid, $1.15 \mathrm{~g}$ disodium tartrate dihydrate, $2.42 \mathrm{~g}$ Tris, and $0.58 \mathrm{~g}$ sodium chloride was added slowly with continuous stirring. The ion electrode was inserted into the solution after all of the reagents were dissolved and the indication of $\mathrm{F}^{-}$ion concentration was recorded. Calibration curves were prepared for each amount of TISAB reagent added by using 10 and $100 \mathrm{mg} \mathrm{L}^{-1} \mathrm{~F}^{-}$standard solutions without aluminum.

The experimental results are shown in Fig. 6. The apparent recovery of $\mathrm{F}^{-}$for a solution containing $10 \mathrm{mg} \mathrm{L}^{-1}$ of $\mathrm{F}^{-}$and $80 \mathrm{mg} \mathrm{L}^{-1}$ of $\mathrm{Al}^{3+}$ was about $99 \%$. However, the apparent recovery of $\mathrm{F}^{-}$decreased to 97,89 , and $74 \%$ at 100,250 , and $500 \mathrm{mg} \mathrm{L}^{-1}$ of $\mathrm{Al}^{3+}$, respectively, at a standard amount of tartrate. In contrast, the apparent recovery of $\mathrm{F}^{-}$was as high as 99,98 , 95 , and $93 \%$ at $80,100,250$, and $500 \mathrm{mg} \mathrm{L}^{-1}$ of $\mathrm{Al}^{3+}$ when the amount of tartrate was four-times the standard amount.

The total amount of tartrate was increased to four-times the standard amount by adding twice the tartaric acid and six times the disodium tartrate. At the same time, the amount of Tris was increased to twice the standard amount. After these modifications, the apparent recovery of $\mathrm{F}^{-}$reached $100,98,97$, 


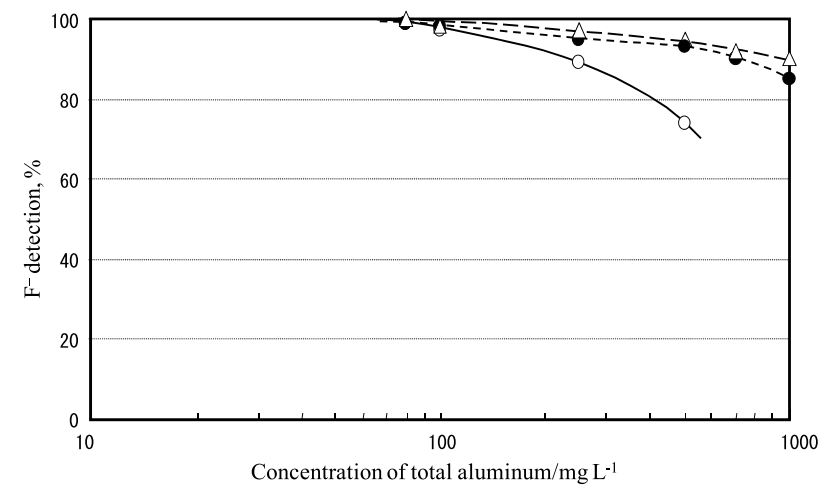

Fig. 6 Effect of the concentration of aluminum on the detection degree of $\mathrm{F}^{-}$in solid TISAB addition methods. Concentration of fluoride in sample solutions, $10 \mathrm{mg} \mathrm{L}^{-1}$. Solid TISAB mixtures were added to $50 \mathrm{~mL}$ of sample solutions. Composition of solid mixtures, tartaric acid/sodium tartrate dehydrate/Tris/sodium chloride: $\odot, 0.75 \mathrm{~g}$ $(5 \mathrm{mmol}) / 1.15(5) / 2.42(20) / 0.58(10) ; \bullet, 1.5 \mathrm{~g}(10 \mathrm{mmol}) / 6.9$ (30)/ 2.42 (20)/0.58 (10); $\triangle, 1.5 \mathrm{~g} \mathrm{(10} \mathrm{mmol)/6.9} \mathrm{(30)/4.84} \mathrm{(40)/0.58} \mathrm{(10).}$

95,92 , and $90 \%$ at $80,100,250,500,700$, and $1000 \mathrm{mg} \mathrm{L}^{-1}$ of $\mathrm{Al}^{3+}$, respectively. This may have been due to the formation of mixed aluminum-ligand complexes, as was assumed by Corbillon et al. ${ }^{15}$

Precision test. For solutions containing 1 and $10 \mathrm{mg} \mathrm{L}^{-1}$ of $\mathrm{F}^{-}$ together with $100 \mathrm{mg} \mathrm{L}^{-1}$ of $\mathrm{Al}^{3+}$, 96 and $97 \%$, respectively, were recovered, when the standard amount of solid TISAB was added. For a solution containing $1 \mathrm{mg} \mathrm{L}^{-1}$ of $\mathrm{F}^{-}$and $500 \mathrm{mg} \mathrm{L}^{-1}$ of $\mathrm{Al}^{3+}$, the recovery of $\mathrm{F}^{-}$reached $95 \%$, and the relative standard deviation was $1.6 \%$ for five independent determinations when a solid TISAB consisting of $1.5 \mathrm{~g}$ tartaric acid, $6.9 \mathrm{~g}$ disodium tartrate dihydrate, $4.84 \mathrm{~g}$ Tris, and $0.58 \mathrm{~g}$ sodium chloride was added to $50 \mathrm{~mL}$ of the sample solution. According to the calculation results, the ratio of free fluoride reached $99.3 \%$ under these conditions.

Effects of coexisting ions. We investigated the effects of coexisting ions on the determination of $\mathrm{F}^{-}$using the standard solid TISAB addition method. $100 \mathrm{mg} \mathrm{L}^{-1}$ of $\mathrm{SO}_{4}{ }^{2-}, \mathrm{NO}_{3}{ }^{-}$, $\mathrm{B}_{4} \mathrm{O}_{7}{ }^{2-}, \mathrm{PO}_{4}{ }^{3-}, \mathrm{SiO}_{3}{ }^{2-}$, and $\mathrm{F}_{\mathrm{e}}^{3+}$ did not interfere with the determination of $10 \mathrm{mg} \mathrm{L}^{-1}$ of $\mathrm{F}^{-}$. $\mathrm{Cl}^{-}$did not interfere with the determination of $\mathrm{F}^{-}$when the additional concentration was as high as $3000 \mathrm{mg} \mathrm{L}^{-1}$. The apparent recovery of $\mathrm{F}^{-}$reached 100 and $98 \%$ at 100 and $3000 \mathrm{mg} \mathrm{L}^{-1}$ of $\mathrm{Ca}^{2+}$, respectively. It was as high as 98 and $96 \%$ at 50 and $100 \mathrm{mg} \mathrm{L}^{-1}$ of $\mathrm{Mg}^{2+}$, respectively. The apparent recovery of $\mathrm{F}^{-}$, however, decreased to $68 \%$ at $1000 \mathrm{mg} \mathrm{L}^{-1}$ of $\mathrm{Mg}^{2+}$. The apparent recovery of $\mathrm{F}^{-}$ was 100,98 , and $74 \%$ at 50,100 , and $1000 \mathrm{mg} \mathrm{L}^{-1}$ of $\mathrm{Mg}^{2+}$, respectively, when a solid TISAB consisting of $1.5 \mathrm{~g}$ tartaric acid, $6.9 \mathrm{~g}$ disodium tartrate dihydrate, $4.84 \mathrm{~g}$ Tris, and $0.58 \mathrm{~g}$ sodium chloride was added to $50 \mathrm{~mL}$ of sample solution. The interference from $\mathrm{Mg}^{2+}$ could not be explained by equilibrium calculations based on the formation of $\mathrm{MgF}^{+}$.

Applications to real samples. A simulated wastewater from a flue gas desulfurization plants for coal-fired boilers was prepared by mixing sodium fluoride, potassium hydrogensulfate, magnesium chloride, calcium chloride, aluminum sulfate, ferrous sulfate, and sulfuric acid. The composition of the simulated wastewater was as follows: $\mathrm{Na}^{+} 341, \mathrm{~K}^{+} 23, \mathrm{Mg}^{2+} 454$, $\mathrm{Ca}^{2+}$ 569, $\mathrm{Al}^{3+}$ 208, total $\mathrm{Fe} 80, \mathrm{Cl}^{-} 1,167, \mathrm{SO}_{4}{ }^{2-} 6775, \mathrm{~F}^{-}$ $341 \mathrm{mg} \mathrm{L}^{-1}$, and $\mathrm{pH} 0.7$. The apparent recovery of fluoride reached $92.3,98.5$, and $99.4 \%$ in sample solutions that were diluted with water to $1 / 5,1 / 10$, and $1 / 20$ of the initial concentration. These results are reasonable, taking the effects of coexisting magnesium and aluminum ions into consideration.

\section{Determination of total fluoride in solid silicate samples}

Incinerator ashes, such as coal ash, usually contain fluoride at levels ranging from 10 to $500 \mathrm{mg} \mathrm{kg}^{-1}$. The typical analytical procedure for these samples is as follows: silicate samples are subjected to alkali fusion with an equimolar mixture of sodium carbonate and potassium carbonate, and then digested to dissolve the fused product. These sample solutions contain sodium, potassium, and carbonate ions, in addition to aluminum, calcium, and silicate.

The interference effects of these ions on the ISE determination of fluoride can be eliminated by steam distillation. With appropriate selection of a TISAB solution, these effects can be drastically reduced. As shown above, the recovery rate of fluoride can achieve $95 \%$ or more by adding a suitable amount of tartrate- and Tris-based TISAB even when the concentration of aluminum reaches $500 \mathrm{mg} \mathrm{L}^{-1}$. The applicability of the ISE method for determining fluoride in solid silicate samples without distillation is discussed below.

Effect of alkali flux. An artificial solid silicate consisting of 30 wt $\% \mathrm{Al}_{2} \mathrm{O}_{3}, 20 \mathrm{wt} \% \mathrm{CaO}$, and $50 \mathrm{wt} \% \mathrm{SiO}_{2}$ was prepared with $400 \mathrm{mg} \mathrm{kg}^{-1} \mathrm{NaF}$. A $0.5 \mathrm{~g}$ sample of this mixture was placed in a platinum crucible and fused with $5 \mathrm{~g}$ of a flux consisting equimolar amounts of sodium carbonate and potassium carbonate. The fused product was dissolved in water and diluted to $200 \mathrm{~mL}$. Thus, the total composition of the solution was as follows: $\mathrm{F}^{-} 1, \mathrm{Al}^{3+} 392, \mathrm{Ca}^{2+} 357, \mathrm{Na}^{+} 4710, \mathrm{~K}^{+} 8020, \mathrm{SiO}_{3}{ }^{2-}$ $1580, \mathrm{CO}_{3}{ }^{2-} 12300 \mathrm{mg} \mathrm{L}^{-1}$.

When analyzed according to the standard ISE procedure for solid TISAB addition method, the measured concentration of fluoride reached $1.41 \mathrm{mg} \mathrm{L}^{-1}$. Measurements on a blank solution in the absence of fluoride resulted in a measured value of $0.92 \mathrm{mg} \mathrm{L}^{-1}$. These results showed the interference of carbonate due to the sample alkalinity. The $\mathrm{pH}$ of the test solution was 9.3 , and a $50-\mathrm{mL}$ aliquot of the dissolved artificial silicate solution described above contained $10.25 \mathrm{mmol}$ of carbonate.

Tartrate can be added not only to decompose fluoroaluminate complexes, but also to remove carbonates. Forty millimoles each of tartrate (finally $10 \mathrm{mmol}$ as the free acid) and Tris should be added to a $50-\mathrm{mL}$ sample of dissolved silicate since the sample also contains a large amount of aluminum; $10.25 \mathrm{mmol}$ of tartaric acid was necessary to release the carbonates used in the alkali fusion process. Thus, to regulate the $\mathrm{pH}$ of the solution and to control the decomposition of carbonates without special processing, $40 \mathrm{mmol}$ of tartrate was added as $20.25 \mathrm{mmol}$ of tartaric acid and $19.75 \mathrm{mmol}$ of the neutral salt.

Effect of coexisting materials. Real sample solutions for fluoride analyses may contain significant levels of $\mathrm{Al}^{3+}, \mathrm{Ca}^{2+}, \mathrm{SiO}_{3}{ }^{2-}$, $\mathrm{Na}^{+}$, and $\mathrm{K}^{+}$originating from the alkali flux decomposition of solid silicates. To study the effects of these ions on fluoride ISE measurements, a sample solution was prepared containing the following concentrations of ions: $\mathrm{F}^{-} 1, \mathrm{Na}^{+} 4710, \mathrm{~K}^{+} 8020$, $\mathrm{CO}_{3}^{2-} 12300 \mathrm{mg} \mathrm{L}^{-1}$. The calibration curve was generated from standard fluoride solutions containing suitable amounts of $\mathrm{Na}_{2} \mathrm{CO}_{3}$ and $\mathrm{K}_{2} \mathrm{CO}_{3}$.

The detection efficiency for fluoride reached $94.7 \%$ in the presence of $500 \mathrm{mg} \mathrm{L}^{-1} \mathrm{Al}^{3+}$. The efficiency reached 98.3 and $99.0 \%$ in the presence of $400 \mathrm{mg} \mathrm{L}^{-1} \mathrm{Ca}^{2+}$ and $1500 \mathrm{mg} \mathrm{L}^{-1}$ of $\mathrm{SiO}_{3}{ }^{2-}$, respectively. The aluminum concentration of the sample solutions obtained in the analysis of common silicate samples is 
Table 2 Analysis of total fluoride in geochemical reference samples using the proposed ISE method

\begin{tabular}{lrrrrr}
\hline & \multicolumn{5}{c}{ Content of total fluoride/mg kg-1 } \\
\cline { 2 - 6 } Sample & $\begin{array}{c}\text { Recommended } \\
\text { value }\end{array}$ & No. 1 & \multicolumn{1}{c}{ Analysis } & 3 & Average \\
& 253 & 248 & 251 & 242 & 247 \\
JB-3 & 589 & 644 & 649 & 648 & 647 \\
JLk-1 & 3200 & 4206 & 4250 & 4187 & 4215 \\
JSd-3 & & & & & \\
\hline
\end{tabular}

lower than $500 \mathrm{mg} \mathrm{L}^{-1}$, showing that the detection efficiency of fluoride reaches more than $95 \%$ for common silicate samples. Corrections for the concentration of matrix compounds may further enhance the reliability of the analytical results.

Analysis of reference samples. Sample solutions were prepared from basalt (JB-3), lake sediment (JLk-1), and stream sediment (JSd-3) according to the procedure shown above. The concentration of aluminum in the sample solutions were 228 , 221 and $131 \mathrm{mg} \mathrm{L}^{-1}$ for JB-3, JLk-1 and JSd-3, respectively. The degree of interference from aluminum at this level of concentration was estimated to be lower than $3 \%$. The fluoride concentration in each sample was determined by ISE and compared with the reported fluoride content of the original solid sample. The results are given in Table 2 .

The experimental results were similar to the reported results for JB-3. However, the experimental results for JLk-1 and JSd-3 showed a higher fluoride content than the reported values. The reason why our analytical results are higher than the recommended values may be due to the fact that the recommended values are the averages of all reported values, regardless of their quality. The maximum deviation from the average were 17 and $62 \%$ in JLk-1 and JSd-3, respectively (see Table 1). Most of the reported values were satisfactorily close to our results.

We conclude that the present method can be applied to the analysis of fluoride in various environmental samples, considering that the Clarke number of fluoride is $300 \mathrm{mg} \mathrm{kg}^{-1}$, and the environmental quality standard for the public water supply is as low as $0.8 \mathrm{mg} \mathrm{L}^{-1}$ in Japan.

\section{Conclusion}

A method for determining fluoride with ion-selective electrodes (ISEs) was studied. Tartrate and Tris-based total ionic strength adjustment buffers (TISABs) were found to lower the interference from aluminum to a greater extent than conventional citrate-based TISABs.

We were able to determine the fluoride content in solid silicate samples with ISEs without preliminary steam distillation after alkali fusion processing. Adding a suitable solid TISAB mixture consisting of tartaric acid, sodium tartrate, and Tris eliminated any interference from high levels of aluminum as well as from sodium and potassium carbonates.

We have clarified that the present analytical method could be applied to the determination of fluoride in wastewater samples from flue gas desulfurization plants for coal-fired boilers and geochemical reference samples.

In order to remove fluoride from wastewater via precipitation and/or adsorption, the fluoride content must be determined in the presence of aluminum. The same is true for investigations of the dissolution behavior of fluoride from solid materials, e.g. fly ash, soil, and sludge. We hope the present method can be applied widely in many fields.

\section{References}

1. H. Asada and Y. Etoh, Environ. Conserv. Eng., 2000, 29, 283.

2. H. Clemens, L. F. Damiano, D. Gong, and T. W. Matheson, Fuel, 1999, 78, 1379.

3. S. Frant and J. W. Ross, Science, 1966, 154, 1553.

4. ASTM D1179-04, "Standard Test Methods for Fluoride Ion in Water", 2004, American Society for Testing and Materials.

5. JIS K0102, "Testing Methods for Industrial Wastewater", 2003, Japanese Industrial Standard.

6. T. Okutani, C. Tanaka, and Y. Yamaguchi, Talanta, 1989, 36, 973.

7. V. L. Dressler, D. Pozebon, É. L. M. Flores, J. N. G. Paniz, and É M. M. Flores, Anal. Chim. Acta, 2002, 466, 117.

8. H. Hara and C. C. Huang, Anal. Chim. Acta, 1997, 338, 141.

9. M. L. Wen, N. H. Shi, Y. Qin, and C. Y. Wang, Fluoride, 1998, 31, 74

10. Y. Yin, Y. Yao, C. C. Liu, and M. L. Wen, Fluoride, 2001, 34, 114.

11. B. L. Ingram, Anal. Chem., 1970, 42, 1825.

12. M. Rietjens, Anal. Chim. Acta, 1998, 368, 265.

13. J. E. Harwood, Water Res., 1969, 3, 273.

14. H. Nakajima, H. Komatsu, T. Okabe, and J. Dent, J. Dentistry, 1997, 25, 137.

15. M. S. Corbillon, M. P. Carril, J. M. Madariaga, and I. Uriarte, Analyst, 1995, 120, 2227.

16. R. W. Billington, J. A. Williams, A. Dorban, and G. J. Pearson, Biomaterials, 2004, 25, 3399.

17. GSJ Geochemical Reference Samples DataBase: http:// riodb02.ibase.aist.go.jp/geostand/welcome.html.

18. DKK-TOA Corporation MSDS 1004-4, Ion Strength Adjuster, TISAB-11, 2004.

19. H. Hara, K. Yabuuchi, M. Higashida, and M. Ogawa, Anal. Chim. Acta, 1998, 364, 117.

20. M. A. G. T. van den Hoop, R. F. M. J. Cleven, J. J. van Staden, and J. Neele, J. Chromatogr., A, 1996, 739, 241.

21. B. Martin, Biochem. Biophys. Res. Commun., 1988, 155, 1194.

22. S. Desroches, S. Dayde, and G. Berthon, J. Inorg. Biochem., 2000, 81, 301 .

23. J. Katagiri, S. Borjigin, T. Yoshioka, and T. Mizoguchi, $J$. Mater. Cycles Waste Manag., in press.

24. The Chemical Society of Japan, "Kagaku Binran Kisohen", 5th ed., 2004, Maruzen Co., Ltd. 